American Journal of Infectious Diseases 6 (2): 54-56, 2010

ISSN 1553-6203

(C) 2010 Science Publications

\title{
Subcutaneous Injection of Metallic Mercury Mimicking Bacterial Cellulites: A Case Report
}

\author{
${ }^{1}$ Mehdi Haghdoost, ${ }^{1}$ Abolfazl Poorhasan, ${ }^{2}$ Kamyar Ghabili and ${ }^{1}$ Omid Mashrabi \\ ${ }^{1}$ Department of Infectious Diseases, \\ ${ }^{2}$ Tuberculosis and Lung Disease Research Center, \\ Faculty of Medicine, Tabriz University of Medical Sciences, Tabriz, Iran
}

\begin{abstract}
Problem statement: Injection of metallic mercury in the forms of subcutaneous or intravenous has been hitherto reported in less than a hundred cases. Approach: We reported a 19 year old male with history of major depression who subcutaneously injected metallic mercury into his right forearm with suicidal intention. Results: A week later, a mild elevation of creatinine level was noted. Subsequently, mercury deposits were totally removed with all affected tissues and fascia of the right forearm. Later, the creatinine level decreased to the normal range. Conclusion: The present case is an example of suicidal attempt that presented with subcutaneous injection of elemental mercury mimicking bacterial cellulitis. Physicians should consider heavy metal injections when evaluating a patient with history of psychiatric disorders presented with bacterial cellulitis.
\end{abstract}

Key words: Mercury, subcutaneous, injection suicide, cellulitis

\section{INTRODUCTION}

Exposure to heavy metals, whether deliberately or fortuitously, has become an important hazard to human health (Vernon, 2005; Ghabili et al., 2007). Among these, mercury not only may be poisonous to the general population via food and fish, but also it might affect the individuals. The latter might be as a result of suicidal attempt, (Isik et al., 1997; Winker et al., 2002; Ruha et al., 2001; Kayias et al., 2003) occupational accident, (Ellabban et al., 2003; Vano-Galvan et al., 2009) penile augmentation, (Oh et al., 2007) and superstitious beliefs (Prasad, 2004). Injection of metallic mercury in the forms of subcutaneous or intravenous has been hitherto reported in less than a hundred cases since 1923 (Brodkin et al., 2007). We report a case of subcutaneously injected elemental mercury with suicidal intention, presenting with signs of bacterial cellulitis.

\section{MATERIALS AND METHODS}

Case report: A 19 year-old male injected an unknown amount of metallic mercury subcutaneously into his right forearm in an attempt to commit suicide. He was referred to our department with a tender, erythematous, swollen right forearm on the third day post-injection. He stated that his right forearm had been swollen for two days, without giving any history of mercury injection. On admission, physical examination revealed blood pressure $110 / 70 \mathrm{mmHg}$, body temperature $36.7^{\circ} \mathrm{C}$, respiratory rate $18 \mathrm{~min}^{-3}$ and pulse rate $78 \mathrm{~min}^{-3}$. The remainder physical examination as well as the neurologic evaluation findings was unremarkable. Initial laboratory findings were as follows: hemoglobin $13.4 \mathrm{~g} \mathrm{dL}^{-1}$, white blood cell count $8.2 \times 10^{3} \mathrm{~mm}^{-3}$, positive C-reactive protein, firsthour erythrocyte sedimentation rate $24 \mathrm{~mm}$, serum creatinine $0.7 \mathrm{mg} \mathrm{dL}^{-1}$, blood urea $24 \mathrm{mg} \mathrm{dL}^{-1}$. With presumptive diagnosis of bacterial cellulitis, the patient was placed on intravenous cefazolin. On third day of admission and following unsatisfactory response to the administered treatment, radiographic examination showed significant volumes of radio-opaque metallic foreign material in the soft tissues of his right forearm (Fig. 1). Further thorough history taking assisted by a psychiatrist, disclosed the patient's intent to commit suicide by injecting the metallic mercury.

Subsequently, total body radiographic examination was performed which did not reveal any opacity indicating no distant mercury deposition or pulmonary emboli. Hepatic and renal laboratory findings along with urine analysis were within normal range. On seventh day of admission, a mild elevation of creatinine level $\left(1.5 \mathrm{mg} \mathrm{dL}^{-1}\right)$ was noted. The following day, the patient was taken to the operating room.

Corresponding Author: Mashrabi Omid, Department of Infectious Diseases, Faculty of Medicine,

Tabriz University of Medical Sciences, Tabriz, Iran Tel: +98-9144049694/+98-4226226106 


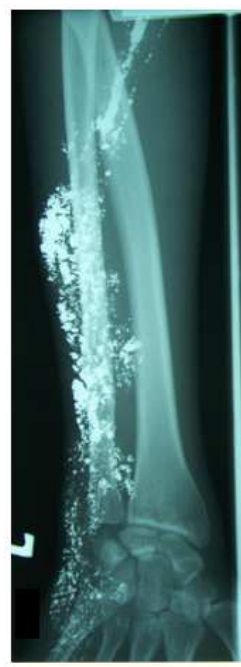

(A)

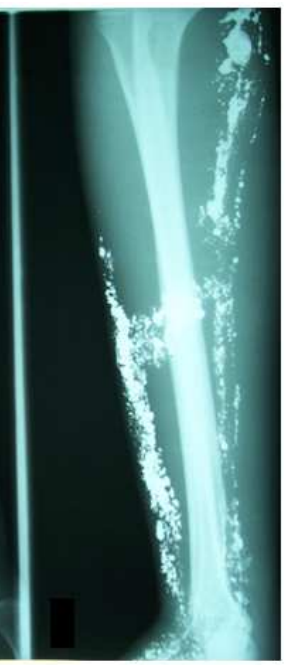

(B)
Fig. 1: (A) Antero posterior view and (B) lateral view of right forearm demonstrating scattered deposits of metallic mercury

There, mercury deposits were removed with all affected tissue and fascia of the right forearm. One month postoperative, the creatinine level decreased to the normal range. He was discharged with a favorable clinical condition.

\section{RESULTS AND DISCUSSION}

Mercury, a chemical agent, is broadly used in industry, agriculture (fungicide-pesticides) and laboratories (Vernon, 2005) In medicine, mercury was once used in the treatment of syphilis and then has been confined to dental amalgams, thermometers and dermal antiseptic preparations (Ellabban et al., 2003). Apart from several reports of individual mercury intoxication, a few mass organic mercury poisonings have been recorded following consumption of contaminated fish and bread in Japan and Iraq, respectively (Vernon, 2005). Nonetheless, toxic effects of elemental mercury usually present following subcutaneous or intravenous injection (Isik et al., 1997) Whether accidentally or intentionally (suicidal attempt and/or psychiatric disorder), this route of mercury poisoning infrequently occurs, i.e., less than a hundred cases have been reported since 1923 (Winker et al., 2002) Once the injected metallic mercury is absorbed, it is gradually oxidized into mercuric salts that bind sulfhydryl groups and hinder a number of critical enzymatic processes, particularly in the central nervous system and the kidneys (Ellabban et al., 2003; Vano-Galvan et al., 2009).
The clinical scenario with which mercury poisoning may present depends on the chemical structure of the mercury compound, the amount absorbed and the route of administration (Winker et al., 2002; Vano-Galvan et al., 2009). In case of acute inhalation, vaporized mercury may cause pneumonitis and noncardiogenic pulmonary edema, which can progress to respiratory failure and death (Vano-Galvan et al., 2009; Brodkin et al., 2007). While ingestion of organic or inorganic mercury leads to gastroenteritis, renal, cardiovascular and neurological involvement, orally ingested metallic mercury usually does not induce poisoning symptoms owing to the minimal absorption through the gut (Prasad, 2004; Brodkin et al., 2007). In subcutaneously injected forms, as in our case, the underlying tissue reacts to the mercury through acute inflammation, development of foreignbody giant cells and granuloma formation (Oh et al., 2007; Prasad, 2004). Besides, there is a debate on whether systemic toxicity may be induced following subcutaneous injection of metallic mercury (Ruha et al., 2001; Vano-Galvan et al., 2009). In this report, we described a young male with history of major depression who injected metallic mercury subcutaneously. We also found a mild increase in creatinine level beginning on tenth day of admission, indicating probable involvement of kidneys. He had no pulmonary or neurologic deterioration.

Once subcutaneous mercury injection is confirmed, immediate excision of the subcutaneous areas to which mercury is injected has been highly recommended (Ellabban et al., 2003; Krohn et al., 1980). Afterward, to monitor the systemic toxicity the central nervous system and renal and pulmonary functions should be assessed (Kayias et al., 2003; Ellabban et al., 2003; Krohn et al., 1980). Although controversial, chelation therapy with penicillamine or dimercaptopropanol has been found beneficial in some previous reports (Oh et al., 2007; Krohn et al., 1980) Moreover, psychiatric consultation and treatment might be indicated in some cases (Ellabban et al., 2003; Krohn et al., 1980). In the present case, surgical excision of the surrounding tissues effectively lowered serum creatinine level, without a need for the chelating therapy.

\section{CONCLUSION}

In summary, the present case is an example of suicidal attempt that presented with subcutaneous injection of elemental mercury mimicking bacterial cellulites. Physicians should consider heavy metal injections when evaluating a patient with history of psychiatric disorders presented with bacterial cellulites. 
Disclosure: The researcher reports no conflicts of interest in this study.

\section{REFERENCES}

Brodkin, E., R. Copes, A. Mattman, J. Kennedy and R. Kling et al., 2007. Lead and mercury exposures: Interpretation and action. Can. Med. Assoc. J., 176: 59-63. PMID: 17200393

Ellabban, M.G., R. Ali and N.B. Hart, 2003. Subcutaneous metallic mercury injection of the hand. Br. J. Plast. Surg., 56: 47-49. PMID: 12706151

Ghabili, K., M.M. Shoja and B. Rahimi-Ardabili, 2007. Nickel dust halo surrounding the guitarists: A potential trigger for the guitarists' respiratory problems. Med. Hypotheses, 69: 950-950. PMID: 17399909

Isik, S., M. Guler, S. Ozturk and N. Selmanpakoglu, 1997. Subcutaneous metallic mercury injection: Early, massive excision. Ann. Plast. Surg., 38: 645-648. PMID: 9188983

Kayias, E.H., G.I. Drosos, D. Hapsas and G.A. Anagnostopoulou, 2003. Elemental mercuryinduced subcutaneous granuloma. A case report and review of the literature. Acta. Orthop. Belg., 69: 280-284. PMID: 12879712

Krohn, I.T., A. Solof, J. Mobini and D.K. Wagner, 1980. Subcutaneous injection of metallic mercury. J. Am. Med. Assoc., 243: 548-549. PMID: 7351787
Oh, K.J., K. Park, T.W. Kang, D.D. Kwon and S.B. Ryu, 2007. Subcutaneous metallic mercury injection for penile augmentation. Urology, 69: e3-e4. PMID: 17270654

Prasad, V.L., 2004. Subcutaneous injection of mercury: Warding off evil. Environ. Health Perspect., 112: 1326-1328. PMID: 15345347

Ruha, A.M., D.A. Tanen, J.R. Suchard and S.C. Curry, 2001. Combined ingestion and subcutaneous injection of elemental mercury. J. Emerg. Med., 20: 39-42. PMID: 11165836

Vano-Galvan, S., D. Jimenez-Garca, E. Vano-Galvan and P. Jaen, 2009. Accidental subcutaneous implant of mercury after thermometer trauma. J. Am. Acad. Dermatol., 61: 535-537. PMID: 19700024

Vernon, S.E., 2005. Case report: Subcutaneous elemental mercury injection-clinical observations and implications for tissue disposal from the histopathology laboratory. Ann. Clin. Lab. Sci., 35: 86-90. PMID: 15830714

Winker, R., A.W. Schaffer, C. Konnaris, A. Barth and P. Giovanoli et al., 2002. Health consequences of an intravenous injection of metallic mercury. Int. Arch. Occup. Environ. Health, 75: 581-586. PMID: 12373321 